\title{
Bluetooth Controlled 5 Axis Articulated Robot Manipulator with Adaptive Gripper
}

\author{
Dhanasekar. J, Sengottuvel. P, Priya.V
}

\begin{abstract}
In this paper discuss about the design and fabrication of 5 axis articulated robot manipulator. In this manipulator TRRTR configuration is used with 6 degree of freedom. By using this configuration each point in the work volume can be achieved accurately. A unique advantage in this design we can orient the object after picking the object. This manipulator controlled by Bluetooth plus USB 16 servo controller module by giving the control signal from PC using USB servo controller software. This robotic manipulator is capable of either taking up programs for angular motion using servo motors or it can be controlled manually by providing individual angular motion signal for every motor through Bluetooth. The programs are fed to do repeated sequential jobs while manual control can override the program in necessary situations. It is used as a human hand when human hand cannot perform at crucial situation.
\end{abstract}

Keywords: TRRTR configuration, Kinematics, 16 servo controller,Servo Mechanism, Bluetooth technology.

\section{INTRODUCTION}

Industrial robots are not absolutely androids that imitator of human, but are more anthropomorphic in nature, in the logic that they are designed with similarity to a human hand; and are also unable to make the self-movement[1].

This Robotic arm is capable of either taking up programs for angular motion of the servo motors or it can be controlled completely manually by providing individual angular motion signal for every motor wirelessly through Bluetooth. Programs are fed into the controller do repeated sequential jobs while manual control can override the program in necessary situations by Bluetooth remote control.

Servo motors are fixed in every degree of freedom point to make axial movements [7]. They are connected to a Servo controller using ATMEGA microcontroller. This servo controller provides signals to each servo motors individually.

A Bluetooth trans-receiver is interfaced with the controller to receive the control signal from Bluetooth controller device and feed them to the controller[8].

\section{A. Applications}

Revised Manuscript Received on July 22, 2019

J.Dhanasekar, Department of Mechatronics ,Bharath Institute of Higher Education \& Research,TamilNAdu Email: Jdhanasekar81@gmail.com

Sengottuvel. P Department of Mechatronics ,Bharath Institute of Higher Education \& Research,TamilNAdu Email hodmechatronics@bharathuniv.ac.in

Priya.V, Department of Mechatronics ,Bharath Institute of Higher Education \& Research,TamilNAdu Email: priyaygna14@gmail.com
Robotic arms are widely used in industries where human works are tough and repeated. They are used in conditions and surroundings were human survivals are hard. They can be operated remotely hence they are used in distance control situations. Since they are not hurt, they are used in military, automated industries for assembling, packaging, transporting and so on. Some advanced robotic arms are used in medical fields for surgical purposes.

\section{METHODOLOGY}

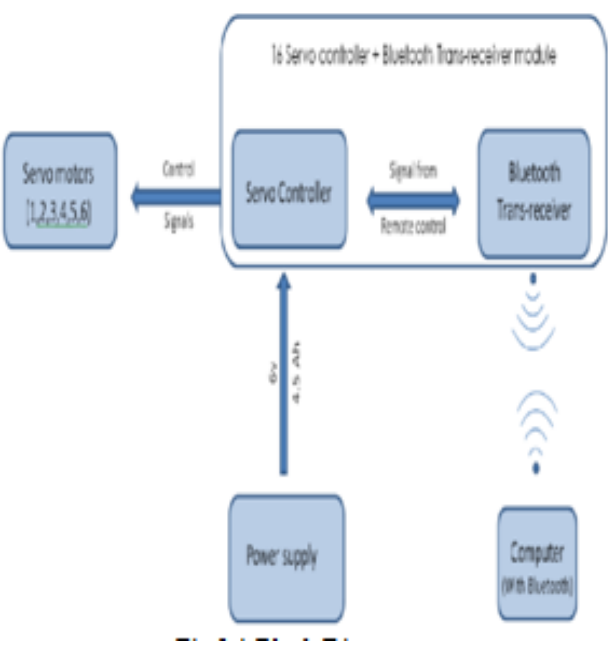

Fig 1:Block Diagram

This robotic arm having 6 servo motors, these servo motors are controlled by servo controller module. This module has the capability to control 16 servo motors. It has the facility of Bluetooth communication between computer and control module. The block diagram of this robotic arm is shown in fig 1

\section{A. Operating \& Working}

i. USB/Bluetooth Servo controller software is installed on a compatible PC. Power supply is given to the controller.

ii. USB cord is connected between the controller and the PC for the Software to recognize the microcontroller device.

iii. The Servo controller is either connected to the PC through USB cable or a Bluetooth connection is established. Blinking light in the controller indicates that the connection is successful.

iv. The software interface shows separate slider for each servo motor that can be slide to control every motor's angular movement. 
v. For making a Sequential program to run, Every step of the motor positions are recorded as a separate movement and all the step movements are made to run in a loop.

vi. Speed and delay for every movement can be changed for our convenience.

\section{B. Servo Mechanism}

A servo system mainly consists of three basic components a controlled device, an output sensor, a feedback system. This is an automatic closed loop control system. Here as a substitute of controlling a device by applying variable input signal, the device is controlled by a response signal generated by comparing output signal and reference input signal. The servo mechanism shown in fig 2

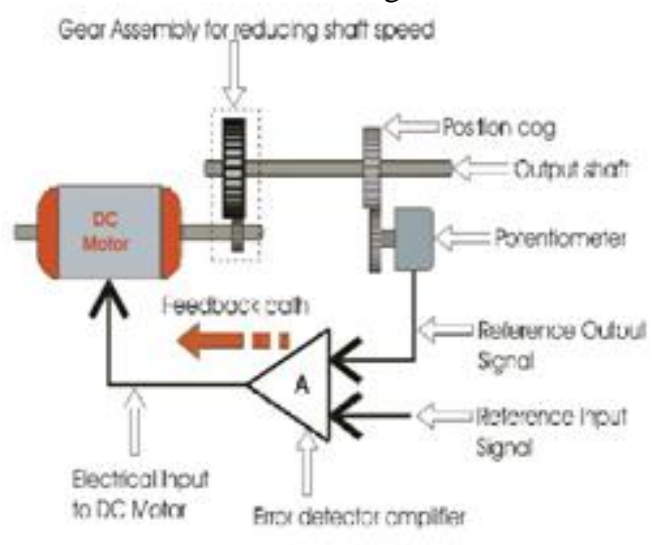

Fig 2 Servo Mechanism

When reference input signal or command signal is useful to the system, it is compared with output reference signal of the system created by output sensor, and a third signal produced by feedback system. This third signal acts as an input signal of controlled device. This input signal to the device presents as long as there is a logical distinction between reference input signal and output signal of the system.

After the device achieves its preferred output, there will be no longer logical variation between reference input signal and reference output signal of the system. Then, third signal produced by comparing these above mentioned signals will not remain enough to operate the device further and to create further output of the system until the next reference input signal or command signal is applied to the system.

Hence the major task of a servomechanism is to maintain the output of a system at the preferred value in the presence of disturbances.

\section{HARDWARE DESIGN}

\section{A. 3D Model}

This model is created by using of Creo software. It shows the various positions of servo motors, gripper, base disc and all links, joints dimensions. The 3D model of robot shows in fig 3

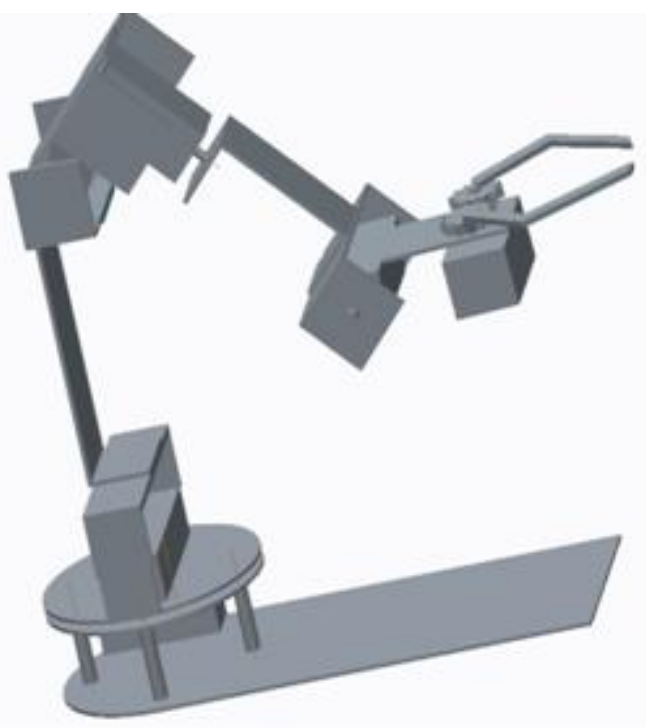

Fig 3:Robot 3D Model

B. Power supply:

The entire servo motors are of 6 volts and with different ampere ratings, a $6 \mathrm{~V}-4.5 \mathrm{Ah}$ Lead-acid batteryhas been used. The power supply is given to the controller circuit and then distributed to each of the servo motors at necessary times. The lead acid battery shown in fig 3

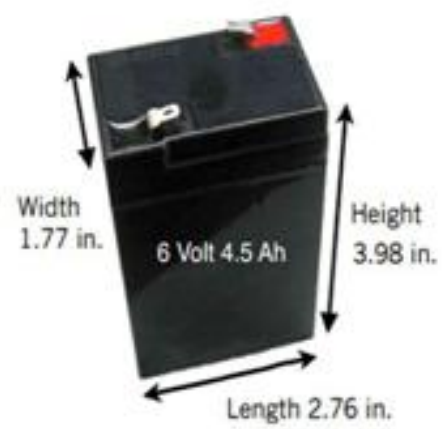

Fig 4:Lead Acid Battery

Each motors Power ratings:

$>$ Motor $1-6 \mathrm{v}, 830 \mathrm{~mA}$

$>$ Motor $2-6 \mathrm{v}, 830 \mathrm{~mA}$

$>$ Motor $3-6 \mathrm{v}, 400 \mathrm{~mA}$

$>$ Motor $4-6 \mathrm{v}, 400 \mathrm{~mA}$

$>$ Motor $5-6 \mathrm{v}, 400 \mathrm{~mA}$

$>$ Motor $6-6 \mathrm{v}, 250 \mathrm{~mA}$

\section{Axis design:}

The axis design for the arm is designed in a way such that the arm is capable of using the full efficiency of the servo motors to move and act smoothly in a convenient movement path. The rotational and the twist movements are fixed in a very efficient manner to obtain a complete flexibility in positioning the target object. Axis design line diagram shown in fig 4 


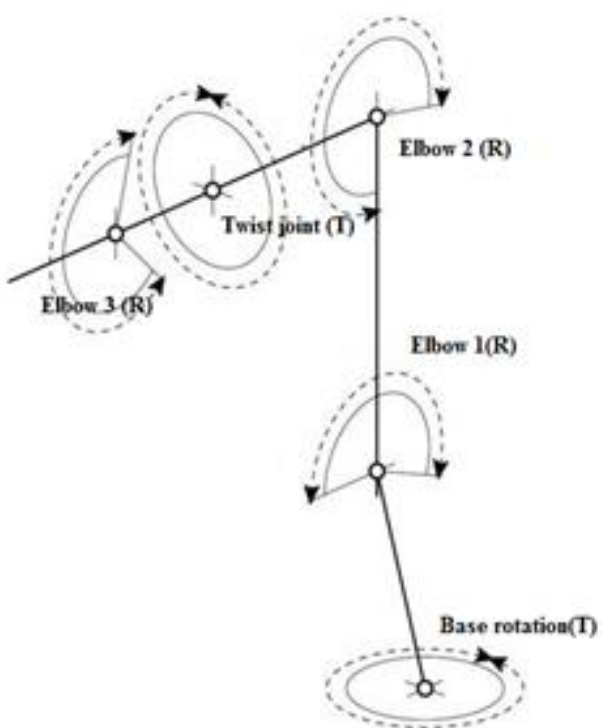

Fig 5 Axis design line diagram

\section{Controller:}

The servo controller used here is capable of connecting 16 servo motors and commanding them individually. It uses Atmega8 microcontroller for controlling the commands fed to them. The program memory is also saved in the microcontroller for sequence programs.

A Bluetooth Trans-receiver is integrated to the controller, which receives signal from a Bluetooth remote controller to control every servo motors individually during manual control. Various parts of this controller module shown in fig 5 Input/output ports:

$>$ Power supply input

$>$ Programmer data input

$>$ Bluetooth signal input

\section{E. SERVO MOTORS OUTPUT}
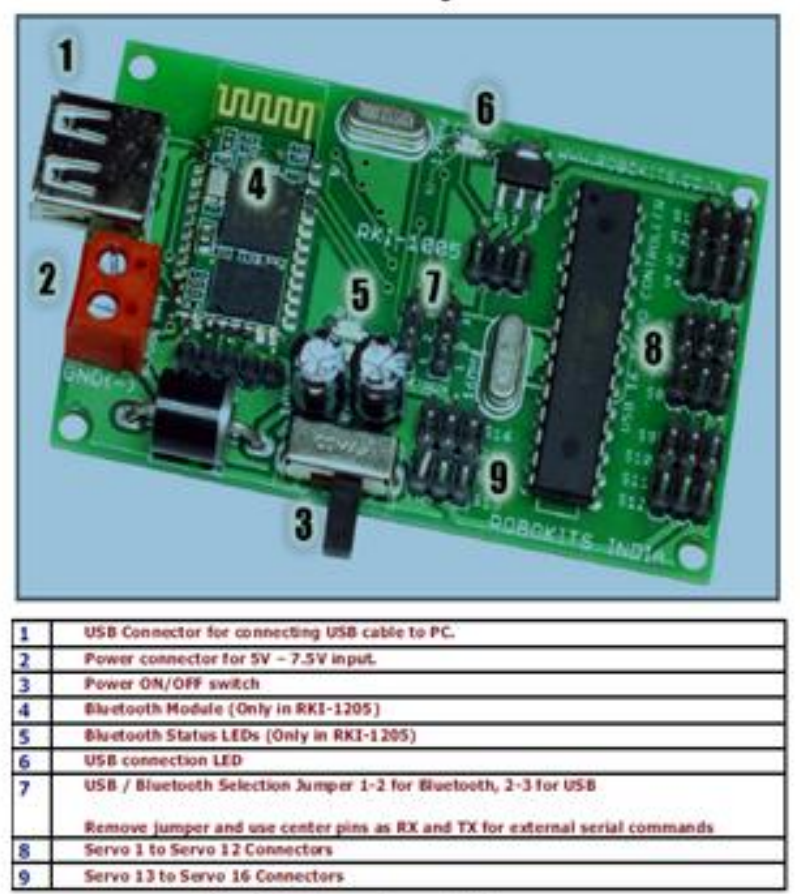

Fig 6:Controller with its parts

\section{Motors:}

Every servo motors get individual angular motion signals from the microcontroller. Each motor is used to make a degree of freedom or as a joint at an end of a link.

$>$ Motor - 1 - Designed to act as elbow

$>$ Motor - 2 - Designed for the Ration of elbow

$>$ Motor - 3 - Designed as elbow joint

> Motor - 4 - Designed for arm up and down motion.

$>$ Motor - 5 - Designed for full axis rotation

> Motor - 6 - Gripper - To hold the object/tool

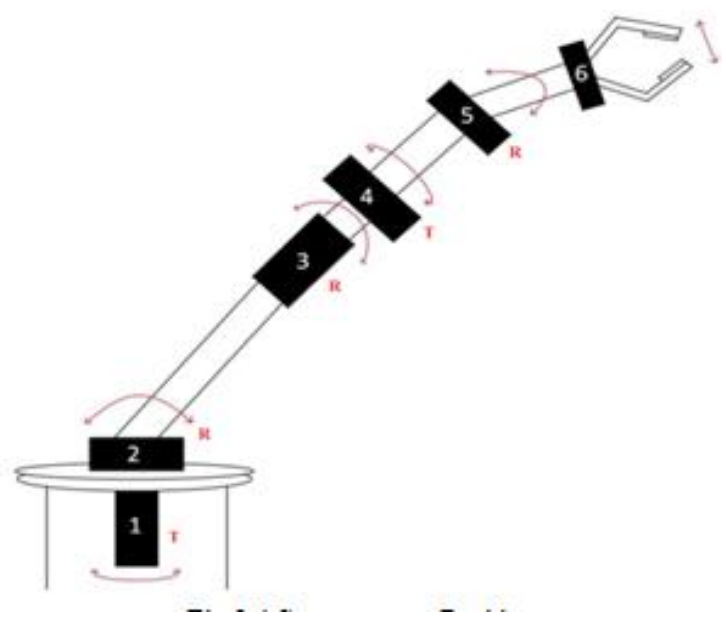

Fig 7: Servo motors Position

\section{F. End Effector:}

The End Effector used in this robotic arm is a Mechanical holding gripper which has many applications such as holding an object, Picking and placing an object and also it can be used as a tool like welding, drilling and screwing Etc... It can also be used as a pointer. The End Effector of a robotic arm can be changed for the convenience of the arm designed to do a specific job. The gripper shown in fig 7

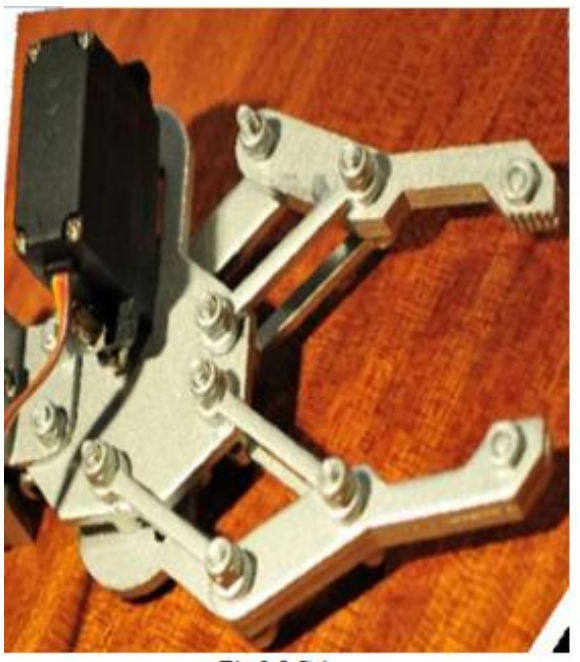

Fig 8 Gripper

Published By:

Blue Eyes Intelligence Engineering \& Sciences Publication 


\section{SOFTWARE}

USB/Bluetooth servo controller software for PC version-5 is used to control the microcontroller either through USB cable or wireless Bluetooth interface.

The software is user-friendly to control and manage each servo motors individually. It has a slider to provide visual feedback of the speed input given to the servomotor through the microcontroller.

It is capable of controlling 16 servo motors also can Record a step-wise movement of a sequence program and reproduce the program in loops to perform a sequential work.

The software can precisely move every servo motor that it can control the $190^{\circ}$ rotation of the servo motor in 1075 points. It is also capable of saving the movement points given to the servo motors in a step-wise manner and running the entire steps in a sequential loop. This helps to save the program and run. The fig 4.1 shows the software front panel with each function blocks representations

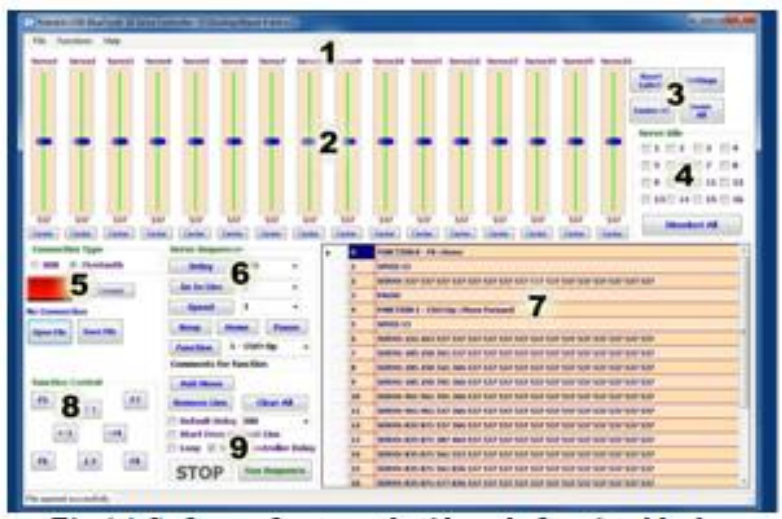

Fig 9: Software front panel with each function blocks

\section{RESULT}

This robot pick and placing the object by controlling the sliderby manual movement

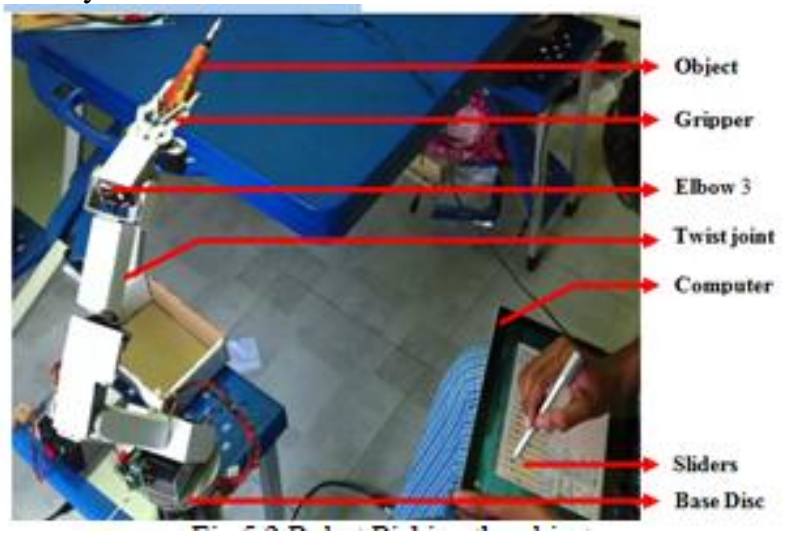

Fig 10: Initial joint position of robot

The each servo motor rotation will be changed by moving the slider up and down in software screen. The initial position and orientation of each servo motor are fixed by placing the slider in different places. Each slider position identified by trial and error method. The Fig 10 shows the initial joint position of the robot. After bringing the robot arm to initial position need to save the slider position for initial arm position and orientation.

\section{CONCLUSION}

From this paper we are obtained how to make the robotic arm and how it's designed. This robot is controlled by servo controller. The robot arm joints are rotated by servo motors. The control signals are sending by the computer using Bluetooth technology. So we can use this type of robotic arm in the field of human inaccessible places..In this robot twisting joint is used before gripper joint. By using this joint can change the orientation of the picked objects as well as orientation of tools

\section{REFERENCES}

1. Sharma, R.K., Irusapparajan, G. \& Periyaazhagar, D. 2019, "Three-phase symmetric cascading Z-source seven levels multilevel inverter excited by multi carrier sinusoidal pulse width modulation scheme", International Journal of Innovative Technology and Exploring Engineering, vol. 8, no. 10, pp. 4269-4274.

2. Velavan, R., Bharanidharan, S. \& Sheeba, B. 2019, "EMF pollution Causes, effects and protection", International Journal of Innovative Technology and Exploring Engineering, vol. 8, no. 9 Special Issue 3, pp. 1166-1168.

3. Saravana, S., Balaji, S., Arulselvi, S. \& John Paul Praveen, A. 2019 "Reliable power quality monitoring and protection system", International Journal of Innovative Technology and Exploring Engineering, vol. 8, no. 9 Special Issue 3, pp. 644-645.

4. Tamil Selvan, S. \& Sundararajan, M. 2019, "Performance Parameters of 3 Value 8t Cntfet Based Sram Cell Design Using H-Spice", International Journal of Recent Technology and Engineering, vol. 8, no. 2 Special issue 5, pp. 22-27.

5. Jac Fredo, A.R., Abilash, R.S., Femi, R., Mythili, A. \& Kumar, C.S 2019, "Classification of damages in composite images using Zernike moments and support vector machines", Composites Part B: Engineering, vol. 168, pp. 77-86.

6. Kathiravan, P. \& Govindaraju, C. 2019, "Design and evaluation of ultra gain isolated DC-DC converter for photovoltaic system", International Journal of Engineering and Advanced Technology, vol. 8, no. 5, pp 2646-2651.

7. Kripa, N., Vasuki, R. \& Kishore Kanna, R. 2019, "Realtime neural interface controlled au-pair BIMA bot", International Journal of Recent Technology and Engineering, vol. 8, no. 1, pp. 992-994.

8. Mohanraj, Meenaa Kumari, M., Philomina, S. \& Jasmin, M. 2019 , "In-situ humidity measurement of hydrogen fuel cell car using MEMS sensor", International Journal of Recent Technology and Engineering, vol. 8, no. 1, pp. 41-43.

9. Velmurugan, T. \& Prakash, S. 2019, "Artificial intelligent based distribution automation of swift fault detection isolation and power restoration for HT network", International Journal of Innovative Technology and Exploring Engineering, vol. 8, no. 6, pp. 1-6.

10. Dwarakesh, K. \& Prem Kumar, G. 2019, "Five-level inverter based sequential boost system using fuzzy logic controller", International Journal of Innovative Technology and Exploring Engineering, vol. 8, no. 6, pp. 12-19.

11. Anne Gifta, A. \& Hemavathi, G. 2019, "Analysis of grid tied solar PV system using ANFIS Algorithm", International Journal of Innovative Technology and Exploring Engineering, vol. 8, no. 6, pp. 312-316.

12. Jayavel, R., Rangaswamy, T.R. \& Prakash, S. 2019, "Efficient grid management system with renewable and conventional power sources", International Journal of Innovative Technology and Exploring Engineering, vol. 8, no. 6, pp. 287-289.

13. Hemavathi, G. \& Maheshwaran, S. 2019, "Proportional resonant controlled high gain step-up converter system with improved response", International Journal of Innovative Technology and Exploring Engineering, vol. 8, no. 6, pp. 317-323.

14. Periyaazhagar, D. \& Irusapparajan, G. 2019, "Design and completion of asymmetric single phase 27 level cascaded mli for various pwm scheme", International Journal of Innovative Technology and Exploring Engineering, vol. 8, no. 6, pp. 792-797.

15. Mahalakshmi, V. \& Vijayaragavan, S.P. 2019, "PV based power electronic converters for high voltage DC applications", International Journal of Recent Technology and Engineering, vol. 7, no. 6, pp 670-674.

16. Irusapparajan, G., Periyaazhagar, D., Prabaharan, N. \& Rini Ann

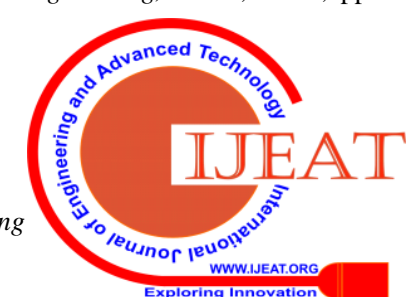


Jerin, A. 2019, "Experimental verification of trinary DC source cascaded h-bridge multilevel inverter using unipolar pulse width modulation", Automatika, vol. 60, no. 1, pp. 19-27.

17. Sangeetha, G., Sherine, S., Arputharaju, K. \& Prakash, S. 2019, "On Line Monitoring of Higher Rated Alternator using Automated Generator Capability Curve Administer", Proceedings of the IEEE International Conference on \&amp;quot;Recent Trends in Electrical, Control and Communication\&amp;quot;, RTECC 2018, pp. 176.

18. Bycil, V.J. \& Wiselin, M.C.J. 2019, "Modeling and analysis of vibration energy harvesting system using piezo stack", International Journal of Mechanical and Production Engineering Research and Development, vol. 9, no. Special Issue 1, pp. 523-533.

19. Sripada, A., Warrier, A., Kapoor, A., Gaur, H. \& Hemalatha, B. 2018, "Dynamic lateral balance of humanoid robots on unstable surfaces", International Conference on Electrical, Electronics, Communication Computer Technologies and Optimization Techniques, ICEECCOT 2017, pp. 539

20. Srinivasan, S., Thirumalaivasan, K. \& Sivakumaran, T.S. 2018, "Performance evaluation of double-output luo converters", Journal of Advanced Research in Dynamical and Control Systems, vol. 10, no. 10 Special Issue, pp. 870-878.

21. Karthikayen, A. \& Selvakumar Raja, S. 2018, "A skellam distribution inspired trust factor-based selfish node detection technique in MANETs", Journal of Advanced Research in Dynamical and Control Systems, vol. 10, no. 13, pp. 940-949.

\section{AUTHORS PROFILE}

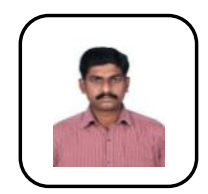

J.Dhanasekar, Assistant Professor,Department of Mechatronics Bharath Institute of Higher Education \& Research,TamilNAdu

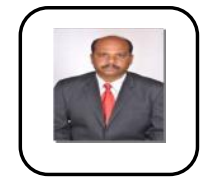

Sengottuvel. P, Professor,Department of Mechatronics Bharath Institute of Higher Education \& Research,TamilNAdu

Priya.V, Assistant Professor,Department of Mechatronics Bharath Institute of Higher Education \& Research,TamilNAdu 